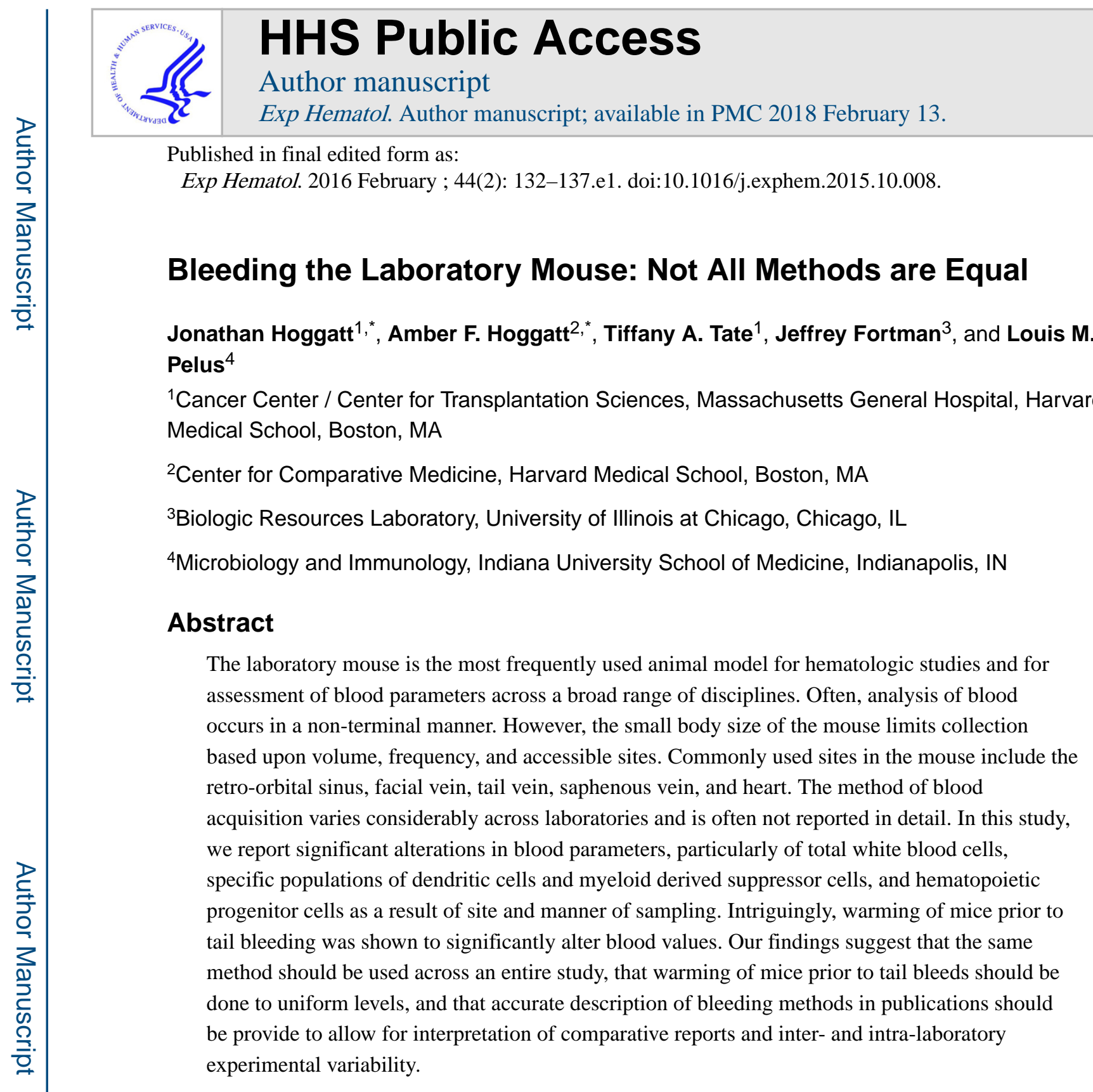

\title{
INTRODUCTION
}

Identifying ways to decrease variability in measured parameters and standardize comparison amongst laboratories are important in order to minimize animal usage and improve data

Correspondence to: Jonathan Hoggatt, Ph.D., Massachusetts General Hospital, Cancer Center / Center for Transplantation Sciences, $14913^{\text {th }}$ Street, CNY 149, Room 5.301, Boston, MA 02129, hoggatt.jonathan@mgh.harvard.edu, Phone: 617-726-6516. Louis M. Pelus, Ph.D., Dept. Microbiology \& Immunology, Indiana University School of Medicine, 950 West Walnut Street, R2-302, Indianapolis, IN 46202, Phone: 317-274-7565, Fax: 317-274-7592, lpelus@ iupui.edu.

These authors contributed equally to this work and should be considered as co-first authors.

\section{Conflict of Interest Disclosures}

The authors declare no competing financial interests.

Publisher's Disclaimer: This is a PDF file of an unedited manuscript that has been accepted for publication. As a service to our customers we are providing this early version of the manuscript. The manuscript will undergo copyediting, typesetting, and review of the resulting proof before it is published in its final citable form. Please note that during the production process errors may be discovered which could affect the content, and all legal disclaimers that apply to the journal pertain. 
evaluation. Age, gender, and strain can affect complete blood count (CBC) and blood chemistry values ${ }^{1-3}$ and is the basis for including animal source and strain in study designs. Common sites for blood collection in mice include the retro-orbital sinus, facial vein (superficial temporal or submandibular veins), tail vein, saphenous vein, and heart (cardiac puncture) ${ }^{2 ; 4-6}$. Classic studies have reported differences in CBC and chemistry values from limited sampling sites in rodents $2 ; 4 ; 7-13$. However, they did not comprehensively evaluate collection sites nor utilize current anesthetics, automated cell counters or flow cytometry. To our knowledge, the effects of warming or sampling method on phenotype-defined blood cells or the effects of bleeding method on blood cell progenitors have not been evaluated. We analyzed hematologic parameters using five common blood sampling sites/methods and compared differences in blood cell populations and function to assess the impact of bleeding method on acquired data.

\section{MATERIALS AND METHODS}

\section{Animals}

All procedures were approved by the Indiana University School of Medicine and University of Illinois at Chicago animal care and use committees. SPFC57B1/6J mice (8 weeks old, average 22 grams) were used (Jackson Laboratories; Bar Harbor, ME). Mice were housed (5/cage) and maintained according to normal barrier rodent husbandry procedures.

\section{Anesthesia}

Isoflurane anesthesia was delivered in $100 \%$ oxygen. Induction was achieved using an induction box and $4 \%$ isoflurane until the mouse was non-responsive, recumbent, and demonstrated a slowed, even respiratory pattern. Anesthesia was maintained using a nose cone and $1-2 \%$ isoflurane.

\section{Blood collection}

Bleeding techniques and use of anesthetics and analgesics were consistent with current veterinary recommendations. All mice used in these studies were naïve to prior bleeding. For all procedures, approximately $100 \mu \mathrm{l}$ blood was collected, as measured using either marked capillary pipettes or a syringe, and was immediately placed in EDTA coated tubes (BD Microtainer \#365974) and thoroughly mixed. The same two skilled researchers performed all bleeds in this study.

Retro-orbital-Mice were anesthetized with isoflurane and a drop of $0.5 \%$ proparacaine hydrochloride ophthalmic solution (Bausch \& Lomb, Tampa, FL) applied 5 minutes prior to sampling. Blood was collected into EDTA capillary pipettes (Drummound Scientific, Broomall, PA). Anesthetized mice were restrained in a fashion that created proptosis of the eye, a capillary tube was inserted at the lateral canthus and the sinus punctured with gentle pressure and twisting motion.

Facial vein-A small hairless area on the ventral jaw of unanesthetized mice was identified as a landmark as described ${ }^{6}$. A $5 \mathrm{~mm}$ lancet (Medipoint Inc., Mineola, NY) was used to 
puncture the vessel slightly caudal and dorsal to the landmark and blood collected cutaneously using capillary pipettes.

Distal tail--cold-A modified tail-clip procedure was used ${ }^{4}$. Briefly, $2.5 \%$ Lidocaine and 2.5\% Prilocaine (EMLA) cream (Hi-Tech Pharmacal Co., Inc, Amityville, NY) was applied topically to the distal $0.5 \mathrm{~cm}$ of tail 15 minutes prior to bleeding. A $\leq \mathrm{mm}$ portion was amputated with surgical scissors and blood collected using capillary pipettes.

Distal tail--warm-Warming was achieved by evenly heating an empty cage to a floor temperature of $35-40^{\circ} \mathrm{C}$. Mice were placed in the cage for ten minutes, or as described. Blood collection was as outlined above.

Cardiac-Mice were anesthetized with isoflurane and placed in dorsal recumbency and swabbed with 70\% alcohol. A 27 -gauge needle was inserted into the abdominal wall just below the xyphoid process and slightly to the mouse's left side at a $10-25^{\circ}$ angle from the abdominal surface. Slight negative pressure was applied to the syringe until a splash of blood was visualized. $100 \mu \mathrm{l}$ of blood was then collected.

\section{Mobilization}

Peripheral blood stem cell mobilization with granulocyte-colony stimulating factor (G-CSF; Neupogen) was performed and analyzed as we have previously described ${ }^{14}$. Briefly, mice were given subcutaneous treatments of G-CSF $(50 \mu \mathrm{g} / \mathrm{kg})$ twice a day for 4 days. On day 5 , $100 \mu \mathrm{l}$ of peripheral blood was acquired by various bleeding methods, lysed using RBC lysis buffer (StemCell Technologies, \#20120) and defined volumes of blood plated in methylcellulose medium (StemCell Technologies, M3434) for 7 days, and total colony forming cells (CFC) determined.

\section{CBC, Flow Cytometry}

CBC analysis was performed using a Hemavet 950FS (Drew Scientific, Waterbury, CT). Flow cytometry was performed on an LSRII using BD Biosciences antibodies as we described ${ }^{15}$.

\section{Statistical Analysis}

Values are reported as mean \pm sem. Statistical significance was determined by one-way ANOVA with Bonferoni post-hoc analysis and student's t-test where appropriate. Significance was set at $\mathrm{P}<0.05$.

\section{RESULTS}

\section{Effect of Bleeding Method on CBC Values}

To assess the effect of bleeding method on normal peripheral blood cell values, mice were bled by five different methods as described in the methods section. Using central cardiac bleeding as a baseline, comparison of the methods showed that retro-orbital bleeding consistently resulted in the lowest absolute number of white blood cells (WBC), neutrophils, lymphocytes, and monocytes in both male and female mice (Figure 1). Facial bleeding 
yielded results comparable to cardiac. Both methods of tail bleeding produced significantly higher WBC, neutrophils, and lymphocytes, but warming significantly reduced these increases compared to cold tail. The percentages of different cell types were less affected by bleeding method and no difference was noted between tail bleeding methods. In contrast to WBC parameters, total red blood cells and platelets, hematocrit, and hemoglobin concentration, were equivalent for cardiac and retro-orbital, but increased for facial and cold and warm tail. To evaluate whether CBC differences noted for facial, cold tail and warm tail reflected bleeding method or were related to absence of anesthesia (cardiac and retro-orbital were performed under isoflurane), additional mice were bled by either facial, cold tail, or warm tail under isoflurane (Supplemental Figure 1). No significant difference was found in CBC parameters, indicating that alterations are the result of site and manner of sampling.

\section{Effect of Bleeding Method on Blood Cell Populations}

To evaluate lineage-defined population differences, T- and B-cells, myeloid and plasmacytoid dendritic cells (DC), total myeloid cells, myeloid-derived suppressor cells (MDSC) ${ }^{16}$, and monocytes were evaluated by flow cytometry (Figure $2 \mathrm{~A}$ ) for female and male (Figures 2B, 2C) mice. A decreased proportion of DC was observed for both warm and cold tail bleeding, suggesting this method is not ideal for studies evaluating/acquiring DC. Intriguingly, warm tail bleeding produced significantly more MDSC than cardiac, retroorbital, facial and cold tail bleeding. These results demonstrate that not only are total white blood cell values affected by bleeding method, but specific populations of cells can differ amongst sites.

\section{Effect of Mouse Warming on WBC Number}

As shown earlier, warming of the mouse prior to tail bleeding decreases $\mathrm{CBC}$ parameters (Figure 1). Since warming is commonly used to increase tail bleeding efficiency, we evaluated the kinetics of this difference between cold and warm tails. When cage temperature was maintained at $35-40^{\circ} \mathrm{C}$, mice did not reach plateau $\mathrm{WBC}$ values until a minimum of ten minutes of warming (Figure 2D). These results suggest that all mice within a cage must meet a minimum-warming threshold prior to tail bleeding, or variation increases.

\section{Effect of Bleeding Method on Detection of Hematopoietic Progenitors in Blood}

All of the data at this point represent normal blood cell populations in steady state mice. To see if other cellular values could be affected in experimentation by bleeding method, particularly hematopoietic progenitor cells in mice, we treated cohort of mice with G-CSF for 4 days to cause hematopoietic progenitor mobilization into the blood, and then assessed relative values of progenitor content based on bleeding method. Similar to CBC, colony forming cells (CFC) in blood obtained from mice mobilized by G-CSF differed amongst methods. Total CFC and CFU-GM, BFU-E and CFU-GEMM, progenitor cells (HPC), obtained for cardiac and retro-orbital bleeding were equivalent, but cold and warm tail were significantly higher (Figure 2E). Similarly, warming prior to tail bleeding produced lower peripheral HPC compared to non-warmed mice. These data demonstrate that bleeding method can alter other cellular values commonly measured in the blood of mice during experimentation. 


\section{DISCUSSION}

In summary, we present a comprehensive analysis of bleeding methods available for mice and their effect on hematologic parameters. Generally, blood sampled from a central site, e.g., cardiac, yields lower RBC, WBC, and platelets compared to blood sampled peripherally, consistent with previous reports $9 ; 13$. These differences may result from peripheral capillary stasis and resistance ${ }^{9}$, stress response induced by collection technique ${ }^{4}$, or immunological demand of the host at various sites. To our knowledge, the present study is the first to demonstrate significant alterations in WBC phenotypic proportions amongst bleeding methods, particularly decreased DC in tail bleeds and substantially elevated MDSC after warming. We also demonstrate that the bleeding method significantly alters enumeration of functionally defined HPC. Of particular note is our finding on the effect on non-uniform warming of mice and the results obtained from tail bleeding. In a prior experiment in our laboratory mice were being warmed to assess blood recovery posttransplantation, and we initially saw a "step-ladder" pattern in the data; in which the first mouse in a cage had a slightly higher WBC value than the second mouse pulled from the same cage, etc. The result of such a difference is a larger spread in the data, which could result in either missing important biologic effects or requiring larger numbers of mice for analysis. Allowing all of the mice to uniformly warm will reduce this source of data variation.

While, in our hands, cardiac bleeding led to the most consistent results (the lowest deviation) the choice of bleeding method is often dictated by the specific experimental demands. Our results suggest 1 ) that the same method should be used across an entire study (i.e. serial bleeds over time), and mixing results using different methods should not occur; 2) if warming mice prior to tail bleeds, mice should be warmed to a uniform level to reduce variance in blood values; 3 ) these results strongly support the need for accurate description of bleeding methods in publications to allow for experimental reproduction and most importantly for intra and inter-laboratory comparisons.

\section{Supplementary Material}

Refer to Web version on PubMed Central for supplementary material.

\section{Acknowledgments}

This work was supported by NIH grants HL069669 and HL096305 to LMP. JH was supported by NIH Training Grant HL007910 and is currently supported by HL119559. Flow cytometry was performed in the Flow Cytometry Resource Facility of the Indiana University Simon Cancer Center (NCI P30 CA082709).

\section{Abbreviations}

$\begin{array}{ll}\text { CBC } & \text { Complete Blood Count } \\ \text { RBC } & \text { Red Blood Cell } \\ \text { WBC } & \text { White Blood Cell } \\ \text { HPC } & \text { hematopoietic progenitor cell }\end{array}$




\section{References}

1. Grubb SC, Maddatu TP, Bult CJ, Bogue MA. Mouse phenome database. Nucleic Acids Res. 2009; 37:D720-D730. [PubMed: 18987003]

2. O'Connell KE, Mikkola AM, Stepanek AM, Vernet A, Hall CD, Sun CC, Yildirim E, Staropoli JF, Lee JT, Brown DE. Practical Murine Hematopathology: A Comparative Review and Implications for Research. Comparative Medicine. 2015; 65(2):1-18.

3. Doeing DC, Borowicz JL, Crockett ET. Gender dimorphism in differential peripheral blood leukocyte counts in mice using cardiac, tail, foot, and saphenous vein puncture methods. BMC Clin Pathol. 2003; 3:3. [PubMed: 12971830]

4. Abatan OI, Welch KB, Nemzek JA. Evaluation of saphenous venipuncture and modified tail-clip blood collection in mice. J Am Assoc Lab Anim Sci. 2008; 47:8-15.

5. Hoff J. Methods of blood collection in the mouse. Lab Animal. 2000; 29:47-53.

6. Golde WT, Gollobin P, Rodriguez LL. A rapid, simple, and humane method for submandibular bleeding of mice using a lancet. Lab Anim (NY). 2005; 34:39-43.

7. Fernandez I, Pena A, Del TN, Perez V, Rodriguez-Cuesta J. Clinical biochemistry parameters in C57BL/6J mice after blood collection from the submandibular vein and retroorbital plexus. J Am Assoc Lab Anim Sci. 2010; 49:202-206. [PubMed: 20353696]

8. Quimby FH, Goff LG. Effect of source of blood sample on total white cell count of the rat. Am J Physiol. 1952; 170:196-200. [PubMed: 12985884]

9. Smith CN, Neptun DA, Irons RD. Effect of sampling site and collection method on variations in baseline clinical pathology parameters in Fischer-344 rats. II. Clinical hematology. Fundam Appl Toxicol. 1986; 7:658-663. [PubMed: 3803760]

10. Schwabenbauer C. Influence of the blood sampling site on some haematological and clinicalchemical parameters in Sprague-Dawley rats. Comparative Haemotology International. 1991; $1: 112-116$.

11. Schnell MA, Hardy C, Hawley M, Propert KJ, Wilson JM. Effect of blood collection technique in mice on clinical pathology parameters. Hum Gene Ther. 2002; 13:155-161. [PubMed: 11779419]

12. Nemzek JA, Bolgos GL, Williams BA, Remick DG. Differences in normal values for murine white blood cell counts and other hematological parameters based on sampling site. Inflamm Res. 2001; 50:523-527. [PubMed: 11713907]

13. Khan KN, Komoscar WJ, Das I, et al. Effect of bleeding site on clinical pathologic parameters in Sprague-Dawley rats: retro-orbital venous plexus versus abdominal aorta. Contemp Top Lab Anim Sci. 1996; 35:63-66. [PubMed: 16457498]

14. Hoggatt J, Tate TA, Pelus LM. Hematopoietic stem and progenitor cell mobilization in mice. Methods Mol Bio. 2014; 1185:43-64. [PubMed: 25062621]

15. Hoggatt J, Singh P, Sampath J, Pelus LM. Prostaglandin E2 enhances hematopoietic stem cell homing, survival, and proliferation. Blood. 2009; 113:5444-5455. [PubMed: 19324903]

16. Ostrand-Rosenberg S, Sinha P. Myeloid-derived suppressor cells: linking inflammation and cancer. J Immunol. 2009; 182:4499-4506. [PubMed: 19342621] 


\section{HIGHLIGHTS}

- $\quad$ Bleeding method alters measured blood parameters.

- $\quad$ Specific cell populations (i.e. dendritic cells) differ at sampling sites in mice.

- Warming mice prior to tail bleeding significantly changes blood values.

- The same method of bleeding should be used across an entire study.

- $\quad$ Bleeding methods of mice should be reported in manuscript methods. 
A
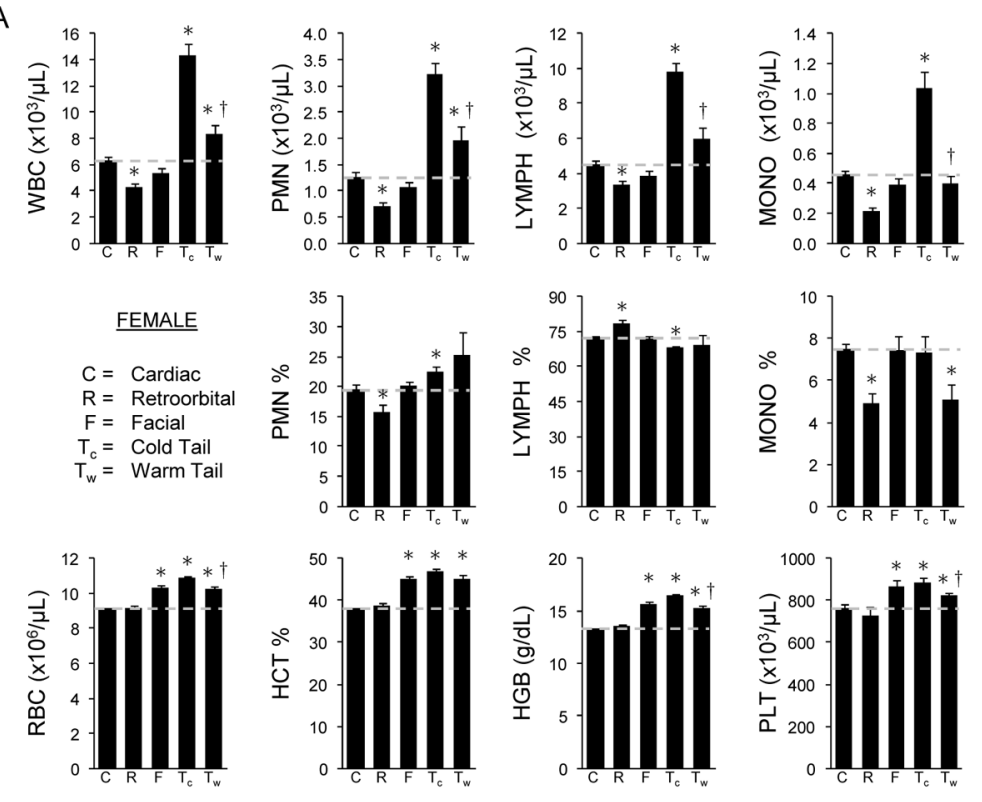

B
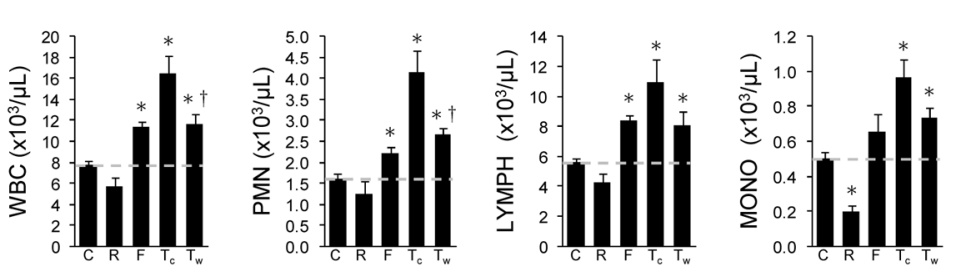

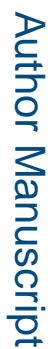
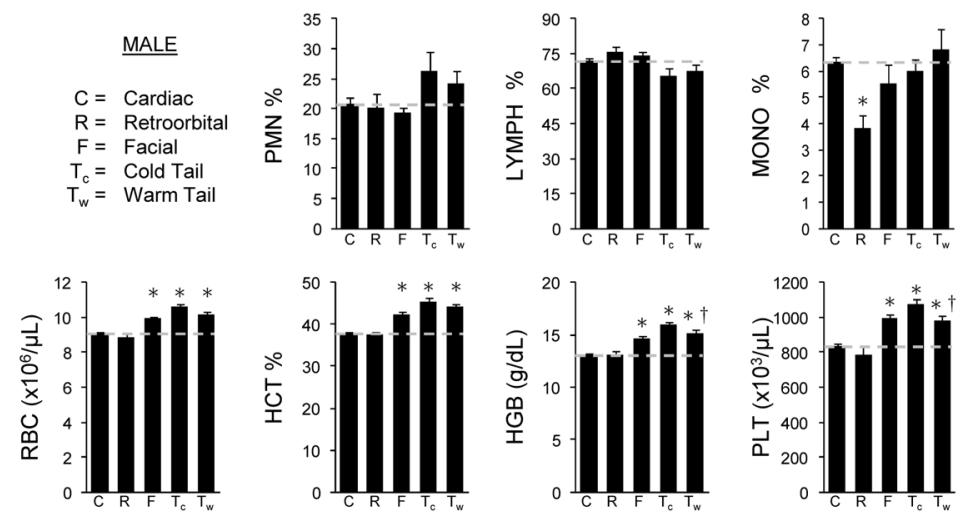

Figure 1.

Comparison of blood cell parameters in C57BL/6 mice using different bleeding methods.

(A) Values represent mean \pm SEM for female mice $(\mathrm{N}=10-35)$. (B) Values represent mean \pm SEM for male mice $(\mathrm{N}=10-30)$ * Significantly different compared to cardiac. $\dagger$

Significantly different from cold tail bleeding method.

Exp Hematol. Author manuscript; available in PMC 2018 February 13. 
A

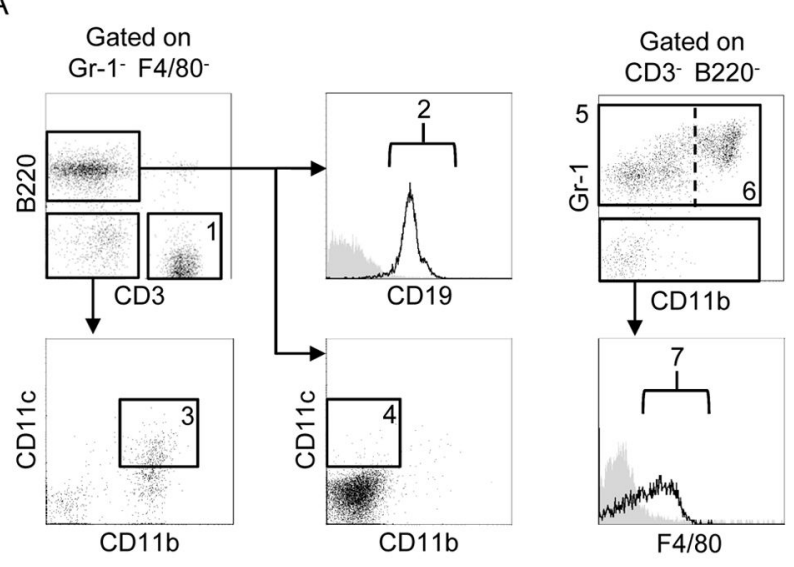

$\mathrm{B}$

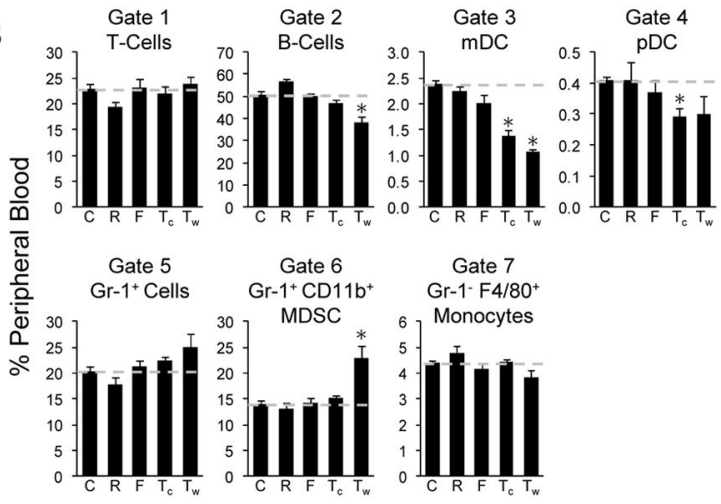

C

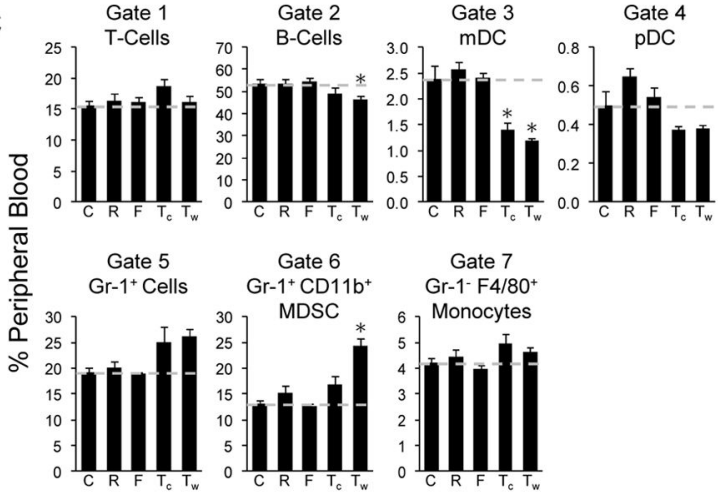

D

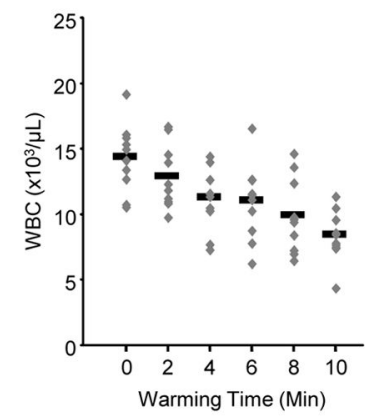

E

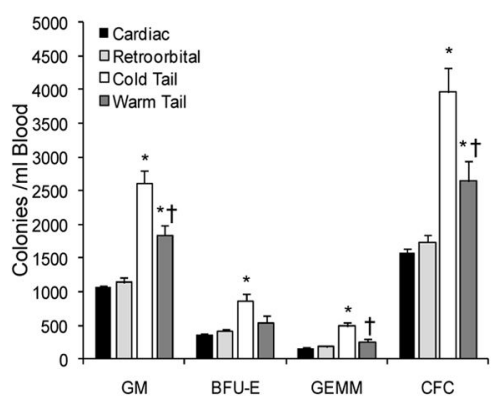

Figure 2.

(A) Representative flow plots showing gating strategy used to define blood cell populations. Gate 1= T-cells $\left(\mathrm{CD}^{+}, \mathrm{Gr}-1^{-}, \mathrm{F} 4 / 80^{-}, \mathrm{B} 220^{-}\right)$; Gate 2 = B-cells $\left(\mathrm{B} 220^{+}, \mathrm{CD} 19^{+}, \mathrm{Gr}-1^{-}\right.$,

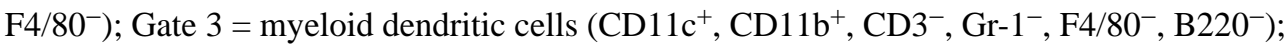
Gate 4 = plasmacytoid dendritic cells $\left(\mathrm{CD} 11 \mathrm{c}^{+}, \mathrm{B} 220^{+}, \mathrm{CD} 11 \mathrm{~b}^{-}, \mathrm{CD}^{-}, \mathrm{Gr}-1^{-}, \mathrm{F} 4 / 80^{-}\right)$; Gate $5=\mathrm{Gr}^{-} 1^{+}$myeloid cells $\left(\mathrm{Gr}-1^{+}, \mathrm{CD}^{-}, \mathrm{B} 220^{-}\right)$; Gate $6=$ myeloid derived suppressor cells $\left(\mathrm{Gr}-1^{+}, \mathrm{CD} 11 \mathrm{~b}^{\text {high }}, \mathrm{CD} 3^{-}, \mathrm{B} 220^{-}\right)$; and Gate $7=$ monocytes $\left(\mathrm{F} 4 / 80^{+}, \mathrm{Gr}^{-} 1^{-}, \mathrm{CD}^{-}\right.$, $\left.B 220^{-}\right)$. Values represent mean \pm SEM for $(B)$ female or $(C)$ male mice $(\mathrm{N}=10,2$ separate experiments). * Significantly different compared to cardiac. (D) Data points represent 
absolute WBC count for individual female mice ( $\mathrm{N}=10,2$ separate experiments) and bars represent mean value for each time point.

(E) Mice were mobilized with 5 injections of G-CSF (125 $\mu \mathrm{g} / \mathrm{kg}$, bid) and CFU-GM, BFUE, CFU-GEMM, and total colony forming cell (CFC) counts determined by methylcellulose colony assay. Values represent mean \pm SEM for female mice $(\mathrm{N}=5)$. * Significantly different compared to cardiac. $\dagger$ Significantly different from cold tail bleeding method. 